\title{
Nutritional variables predict chances of returning home and activities of daily living in post-acute geriatric care
}

This article was published in the following Dove Press journal:

Clinical Interventions in Aging

\author{
Keisuke Maeda ${ }^{1,2}$ \\ Takayuki Koga ${ }^{3}$ \\ Junji Akagi ${ }^{4}$
}

'Palliative Care Center, Aichi Medical University, Aichi, Japan; ${ }^{2}$ Department of Nutrition and Dysphagia Rehabilitation, Tamana Regional Health Medical Center, Kumamoto, Japan; ${ }^{3}$ Department of Swallowing and Nutritional Therapy, Tamana Regional Health Medical Center, Kumamoto, Japan; ${ }^{4}$ Department of Surgery, Tamana Regional Health Medical Center, Kumamoto, Japan
Correspondence: Keisuke Maeda Palliative Care Center, Aichi Medical University, I-I Yazakokarimata, Nagakute, Aichi 480-I 195, Japan $\mathrm{Tel}+8|56| 62331 \mid$

Fax +81561786364

Email kskmaeda@aichi-med-u.ac.jp
Background: Little is known about the association between malnutrition and the chances of returning home from post-acute facilities in older adult patients. This study aimed to understand whether malnutrition and malnutrition-related factors would be determinants for returning home and activities of daily living (ADL) at discharge after post-acute care.

Methods: Patients aged $\geq 65$ years living at home before the onset of an acute disease and admitted to a post-acute ward were enrolled $(n=207)$ in this prospective observational study. Malnutrition was defined based on the criteria of the European Society for Clinical Nutrition and Metabolism. Nutritional parameters included the nutritional intake at the time of admission and oral conditions evaluated by the Oral Health Assessment Tool (OHAT). The Barthel Index was used to assess daily activities. A Cox regression analysis of the length of stay was performed. Multivariable linear regression analyses to determine associations between malnutrition, returning home, and ADL at discharge were performed, after adjusting the variables of acute care setting.

Results: The mean patient age was $84.7 \pm 6.7$ years; $38 \%$ were men. European Society for Clinical Nutrition and Metabolism-defined malnutrition was observed in 129 (62.3\%) patients, and $118(57.0 \%)$ of all patients returned home. Multivariable regression analyses showed that malnutrition was a negative predictor of returning home (hazard ratio: 0.517 [0.351-0.761], $p=0.001)$, and an increase in the nutritional intake $(\mathrm{kcal} / \mathrm{kg} / \mathrm{d})$ was a positive predictor of the Barthel Index at discharge (coefficient: $0.34 \pm 0.15, p=0.021$ ). The OHAT was not associated with returning home and ADL.

Conclusion: Malnutrition and nutritional intake are associated with returning home and ADL at discharge, respectively, after post-acute care. Further studies investigating the effects of a nutritional intervention for post-acute patients would be necessary.

Keywords: geriatric care, malnutrition, patient discharge, nutritional intake, ADL

\section{Introduction}

Many patients, especially older adults, admitted for acute care experience alterations in their residential destinations after medical care. Patients who do not go back home usually get transferred to post-acute care wards/facilities including rehabilitation wards/ facilities. ${ }^{1}$ It has been reported that $26 \%-69 \% \%^{2-4}$ and $18 \%-39 \% 0^{5,6}$ of older adults do not return home from post-acute care and subacute care facilities, which are similar types of settings. Limited mobility, lower activities of daily living (ADL), cognitive impairment, increasing age, male gender, dysphagia, living alone, and medical needs were reported as the factors influencing their chances of returning home. . $^{3,8}$

In addition to several factors, nutritional parameters are potentially associated with returning home from post-acute or subacute settings. A systematic review has shown 
that malnutrition at the time of admission to a rehabilitation ward has a negative effect on the physical functioning of the patients and their destination after being discharged from the ward. ${ }^{1}$ Hakkarainen et $\mathrm{al}^{3}$ have reported in a retrospective study that parenteral nutrition and pressure ulcers are two factors that prevent a patient from returning home. In another prospective study involving 65 older patients in a subacute care facility, Visvanathan et $\mathrm{al}^{5}$ have reported that patients who were positive for a nutrition screen were more likely to be not discharged from the care facility. On the other hand, there was a controversial study that used simple indicators such as body mass index (BMI) and the Mini Nutritional Assessment (MNA) ${ }^{6,9}$ and did not find any association between malnutrition and returning home. It is likely that the variety of tools used to diagnose malnutrition could have contributed to the controversies. ${ }^{1}$ However, to our knowledge, there are only a few studies that have investigated these parameters in elderly Asian patients. ${ }^{1}$ If malnutrition at the time of admission to the post-acute setting is indeed a predictor of the destination after discharge and since many elderly patients requiring post-acute care are malnourished, ${ }^{10}$ it is likely that nutritional intervention can enable these patients to return home. To identify associations between malnutrition and chances of returning home, therefore, will be meaningful for patients in a post-acute setting.

Recently, the European Society for Clinical Nutrition and Metabolism (ESPEN) defined the criteria for the diagnosis of malnutrition after obtaining a consensus from experts, ${ }^{11}$ although there had been no standard definition of malnutrition until then. ${ }^{6}$ Additionally, nutritional status is influenced by multiple factors such as nutritional intake, ${ }^{12} \mathrm{ADL},{ }^{12}$ and oral health. ${ }^{13,14}$ ADL could be associated with both returning home and malnutrition in a post-acute care setting. In order to strengthen the current evidence, we aimed to investigate if malnutrition as defined by ESPEN and malnutrition-related factors such as nutritional dietary intake and oral conditions could be determinants for returning home and ADL at discharge in elderly Asian patients after post-acute care.

\section{Methods}

\section{Design and participants}

A single-center, observational cohort study was conducted in our 150-bed hospital, which includes a 47-bed post-acute care ward in the third largest city of Kumamoto prefecture in Japan. The study started in May 2016, with enrollment and follow-up ending in May and June 2017, respectively. Consecutive patients ( $\geq 65$-years-old) who lived at home before the onset of diseases and were admitted to the post-acute care ward after receiving acute medical care were asked to enroll in the study. Written informed consent was obtained from all patients or their legal guardians, and the study was approved by the ethics committee of the Tamana Regional Health Medical Center (approval ID: TRHMC-280511), in accordance with the Declaration of Helsinki. Patients not providing informed consent or who could not be measured for fat-free mass (FFM) using bioimpedance analysis were excluded from the study.

\section{Sample size calculation}

We used data from an unpublished study of ours which showed that $50 \%$ of the older adults residing in their homes before admission to hospital were discharged back to their homes after post-acute care between May and October 2015. Based on these numbers, we predicted that $40 \%$ and $60 \%$ patients with and without malnutrition, respectively, would be able to return home after care. Under a power $=0.8$ and an $\alpha$ error $=0.05$, the study needed 194 participants, assuming half of the participants would be malnourished. Therefore, we designed the study with 216 enrollments factoring in $15 \%$ exclusions or withdrawals.

\section{Nutritional variables}

Malnutrition was diagnosed according to the definition of ESPEN $^{11}$ by a two-step process. First, a validated nutritional risk screening tool was used, and in the next step, malnutrition was determined by the fulfillment of one or more of the following 3 criteria: 1) BMI (calculated body weight divided by height squared) $<18.5 \mathrm{~kg} / \mathrm{m}^{2}, 2$ ) unintentional weight loss ( $>3 \mathrm{~kg}$ or $>5 \%$, within 3 months) and low BMI (aged $<70$ years, BMI $<20.0 \mathrm{~kg} / \mathrm{m}^{2}$; aged $\geq 70$ years, BMI $<22.0 \mathrm{~kg} / \mathrm{m}^{2}$ ), and 3) unintentional weight loss and low FFM index (female, $<15.0 \mathrm{~kg} / \mathrm{m}^{2}$; male, $<17.0 \mathrm{~kg} / \mathrm{m}^{2}$ ). In this study as well as our previous study, ${ }^{15}$ a Mini Nutritional Assessment-Short Form (MNA-SF) ${ }^{12}$ was used as a screening tool, and the FFM index was calculated. FFM, which was obtained using a multi-frequency bioimpedance instrument, (Inbody S10, Inbody Japan, Tokyo, Japan) divided by height squared gives the FFM index.

Nutritional intake was estimated by the attending dietitian based on each meal consumed during the first 3 days ( 9 meals) in the post-acute care ward. The estimate was based on the consumption rate of the main dish and an accompanying dish, recorded separately by nurses. Usually, the size and type of meal provided in the hospital were determined by an attending doctor and a dietitian. The average calorie intake per actual body weight per day was recorded.

The oral condition was assessed using a validated tool named the Oral Health Assessment Tool (OHAT). OHAT comprises of 8 categories of oral health conditions ranging 
from 0 (best) to 16 (worst). ${ }^{16} \mathrm{~A}$ dental hygienist assessed and recorded the participants' oral condition within 3 days of admission.

\section{Outcomes}

The primary outcome was the ability to return home after post-acute care, including routine nutritional care (nutritional screening and assessment) provided by the dietitians and the nutrition support team. Where each patient moved to after being discharged from the hospital was recorded by the attending nurse in their medical chart. To avoid bias, the medical social workers who were responsible for the patients' residential destinations were blinded to the baseline nutritional parameters such as the presence of ESPEN-defined malnutrition, dietary intake for 3 days at admission, and OHAT. The secondary outcome was ADL at discharge, and we aimed to determine the variables at the time of admission to the post-acute care ward that could influence ADL at discharge. Attending nurses also recorded the Barthel Index
(BI) both at the time of admission and discharge from the ward, as well as premorbid BI. ${ }^{17} \mathrm{BI}$ used in the study ranged from 0 (totally dependent) to 100 (independent) with a 5 point grade based on daily activities.

\section{Measurements}

Each participant's characteristics, including age, sex, the primary reason for admission, the length of stay in acute care ward, and Charlson's comorbidity index, ${ }^{18}$ were collected as variables in the acute care ward. Cognitive impairment was assessed by the attending nurses as a variable at the time of admission to post-acute care ward, using the Cognitive Performance Scale (CPS), ${ }^{19}$ which is an ordinal scale ranging from 0 (intact) to 6 (very severe impairment). Prescription for physical rehabilitation program by physical therapists during hospitalization and the length of stay at the post-acute care ward were also collected as outcome-related variables. Variables obtained in the study and the time points are depicted in Figure 1.

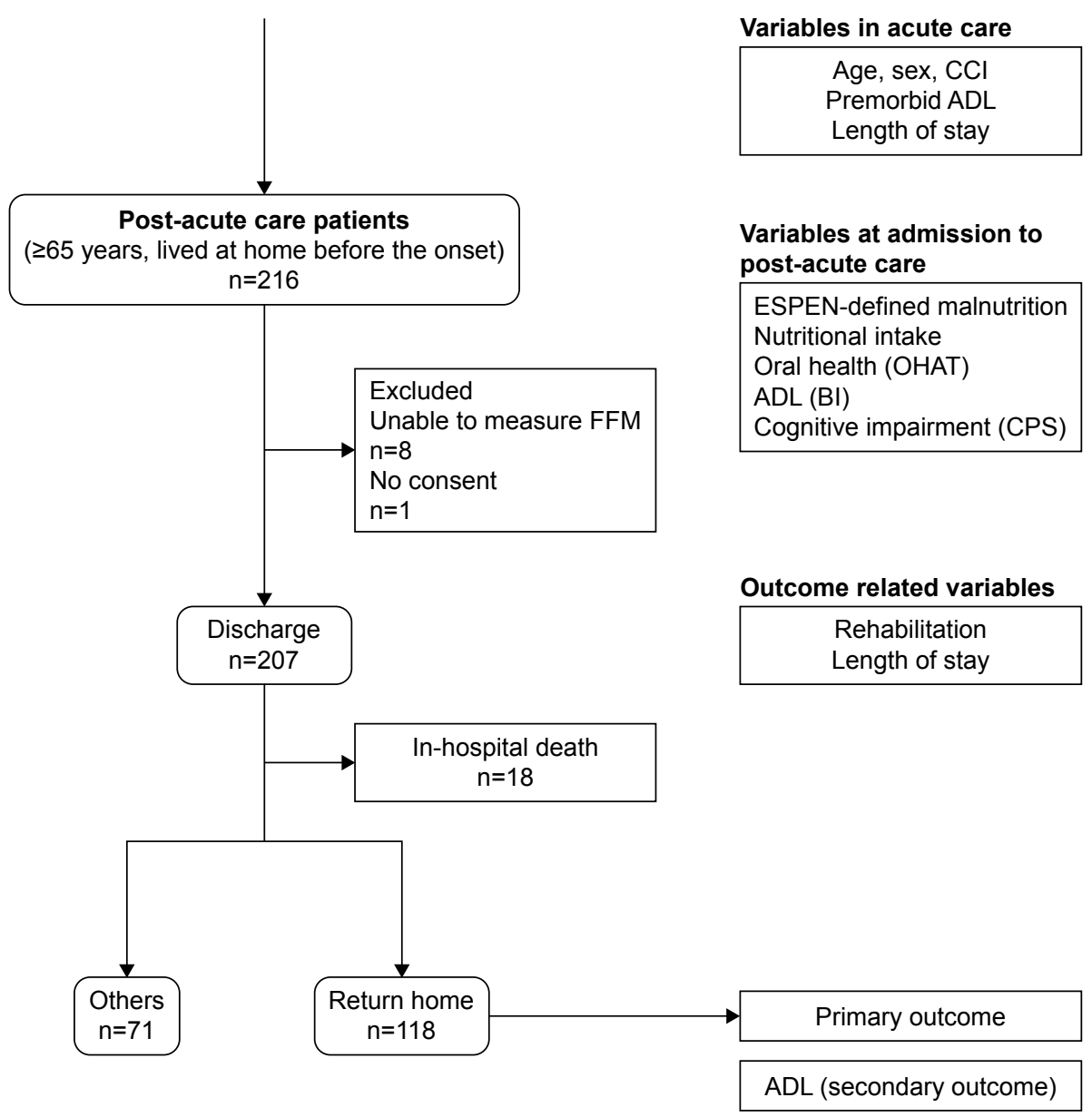

Figure I Study flow diagram and variables collected in the study.

Abbreviations: ADL, activities of daily living; BI, Barthel Index; CCI, Charlson comorbidity index; CPS, Cognitive Performance Scale; FFM, fat-free mass; ESPEN, European Society for Clinical Nutrition and Metabolism; OHAT, Oral Health Assessment Tool. 


\section{Statistical analysis}

Quantitative variables were expressed as a mean \pm standard deviation in cases of parametric distribution or as median [interquartile range] when the distribution was nonparametric. Differences between groups were analyzed using the Welch's $t$-test or the Mann-Whitney's $U$ test. Categorical data were expressed as frequencies (percentages), with between-group differences analyzed using the Fisher's exact test. Separate Cox proportional regression analyses were performed for all cases (including cases resulting in death) and only survival cases after adjusting the length of stay to identify variables that could be measured at the time of admission or during hospitalization. The chances of returning home could be predicted after adjusting all the variables obtained before the enrollment of the study started. Multivariable linear regression analyses were performed after adjusting the variables from the acute care ward, to determine the association between ADL at discharge and the variables examined at the time of admission or during hospitalization. The analysis for ADL at discharge included only survival cases, because examining ADL at discharge in cases that resulted in death is not possible. All statistical analyses were performed using the SPSS software, version 21 (IBM Corp., Armonk, NY, USA); $p<0.05$ was considered statistically significant.

\section{Results}

A total of 216 patients met the three inclusion criteria. Of these, eight patients for whom FFM using a bioimpedance analyzer (metallic instrument in the body) could not be measured, and one patient who did not give consent to enroll were excluded from the study. Finally, 207 participants were evaluated in the study. Table 1 shows the patient characteristics and comparisons between nutritional status groups (intact vs malnutrition). The mean age of the participants was $84.7 \pm 6.7$ years, and $38.2 \%$ of them were men. BI scores indicated that most patients were dependent for ADL before the onset of the disease. Malnourished patients were likely to be inactive based on premorbid $\mathrm{BI}(p<0.001)$ and $\mathrm{BI}$ score at the time of admission to post-acute care ward $(p<0.001)$. The average length of stay at the acute care ward was 18.0 \pm 11.5 days. The major reasons for admission to acute care ward were the same for both the nutritional status groups ( $p=0.665)$ and included infections (25.6\%), physical deconditioning (19.8\%), and nutritional support (15.5\%).

Table I Baseline characteristics of the study participants

\begin{tabular}{|c|c|c|c|c|}
\hline & \multicolumn{3}{|c|}{ Nutritional status } & \multirow[t]{2}{*}{$p$-value } \\
\hline & $\begin{array}{l}\text { Overall } \\
(n=207)\end{array}$ & $\begin{array}{l}\text { Intact } \\
(n=78)\end{array}$ & $\begin{array}{l}\text { Malnutrition } \\
(n=\mid 29)\end{array}$ & \\
\hline \multicolumn{5}{|l|}{ Variables in acute wards } \\
\hline Age, years & $84.7 \pm 6.7$ & $84.3 \pm 6.0$ & $84.9 \pm 7.1$ & 0.535 \\
\hline Male, n (\%) & $79(38.2)$ & $29(37.2)$ & $50(38.8)$ & 0.937 \\
\hline Premorbid $\mathrm{Bl}$, score & $65 \pm 32$ & $75 \pm 27$ & $59 \pm 32$ & $<0.001$ \\
\hline $\mathrm{CCl}$, score & $2.9 \pm 2.0$ & $2.7 \pm 2.0$ & $3.0 \pm 2.3$ & 0.348 \\
\hline Length of stay in acute ward, days & $|8.0 \pm 1| .5$ & $16.2 \pm 9.5$ & $19.1 \pm 12.5$ & 0.084 \\
\hline Reason for admission to acute ward & & & & 0.665 \\
\hline Infections & $53(25.6)$ & $17(21.8)$ & $36(27.9)$ & \\
\hline Malignancy & $20(9.7)$ & $7(9.0)$ & $13(10.1)$ & \\
\hline Physical deconditioning & $41(19.8)$ & $16(20.5)$ & $25(19.4)$ & \\
\hline Nutrition support & $32(15.5)$ & $8(10.3)$ & $24(18.6)$ & \\
\hline Surgery (no malignancy) & $2(1.0)$ & $2(2.6)$ & $0(0.0)$ & \\
\hline Digestive disease & $17(8.2)$ & II (I4.I) & $6(4.7)$ & \\
\hline Cardiovascular disease & $12(5.8)$ & $3(3.8)$ & $9(7.0)$ & \\
\hline Renal disease & $2(1.0)$ & $0(0.0)$ & $2(1.6)$ & \\
\hline Others & $28(13.5)$ & $14(17.9)$ & $14(10.9)$ & \\
\hline \multicolumn{5}{|l|}{ Variables at a post-acute ward admission } \\
\hline Malnutrition, n (\%) & $129(62.3)$ & - & - & \\
\hline Nutritional intake, $\mathrm{kcal} / \mathrm{kg} / \mathrm{d}$ & $25.8 \pm 9.7$ & $23.6 \pm 8.1$ & $27.2 \pm 10.3$ & 0.010 \\
\hline OHAT, score & I (0-2) & $\mathrm{I}(0-2)$ & I $(0-2)$ & 0.806 \\
\hline Bl, score & $47 \pm 32$ & $58 \pm 32$ & $40 \pm 30$ & $<0.001$ \\
\hline CPS, score & $2(0-3)$ & $2(0-2)$ & $2(I-4)$ & 0.001 \\
\hline
\end{tabular}

Notes: Data are presented as mean \pm standard deviation unless otherwise specified. Malnutrition was diagnosed using the ESPEN-defined Malnutrition."

Abbreviations: BI, Barthel Index; CCI, Charlson's comorbidity index; CPS, Cognitive Performance Scale; ESPEN, European Society for Clinical Nutrition and Metabolism; OHAT, Oral Health Assessment Tool. 
Table 2 Relationship between nutritional variables at admission and outcomes at discharge

\begin{tabular}{|c|c|c|c|c|c|c|c|}
\hline & Intact & Malnutrition & $p$-value & $\begin{array}{l}\text { Nutritional } \\
\text { intake } \\
\text { (kcal/kg/d) }\end{array}$ & $p$-value & OHAT & $p$-value \\
\hline \multicolumn{8}{|l|}{ Return home (overall), n (\%) } \\
\hline No & $21(26.9)$ & $68(52.7)$ & $<0.001$ & $24.0 \pm 10.8$ & 0.022 & I (0-2) & 0.152 \\
\hline Yes & $57(73.1)$ & $6 \mid(47.3)$ & & $27.2 \pm 8.6$ & & I (0-2) & \\
\hline \multicolumn{8}{|l|}{ Return home (survival cases), n (\%) } \\
\hline No & $16(21.9)$ & $55(47.4)$ & $<0.001$ & $25.6 \pm 10.8$ & 0.275 & I (0-2) & 0.303 \\
\hline Yes & $57(78.1)$ & $61(52.6)$ & & $27.2 \pm 8.6$ & & I (0-2) & \\
\hline Bl at discharge (survival cases), score & $70 \pm 30$ & $55 \pm 33$ & 0.003 & - & & - & \\
\hline \multicolumn{8}{|l|}{ Length of stay in post-acute ward, days } \\
\hline Survivor $(n=189)$ & $22.9 \pm 20.0$ & $33.2 \pm 20.8$ & 0.001 & - & & - & \\
\hline Nonsurvivor $(n=18)$ & $44.6 \pm 24.0$ & $32.8 \pm 20.9$ & 0.316 & - & & - & \\
\hline \multicolumn{8}{|l|}{ Rehabilitation by PT } \\
\hline Prescribed & $27(37.0)$ & $57(49.1)$ & 0.068 & $27.1 \pm 10.2$ & 0.549 & I (0-2) & 0.329 \\
\hline Not prescribed & $46(63.0)$ & $59(50.9)$ & & $26.2 \pm 8.9$ & & I (0-2) & \\
\hline
\end{tabular}

Note: Data are presented as mean \pm standard deviation unless otherwise specified.

Abbreviations: BI, Barthel Index; OHAT, Oral Health Assessment Tool; PT, physical therapist.

Malnourished patients were likely to have a higher nutritional intake $(p=0.010)$ and revealed lower cognitive functions ( $p=0.001$ ) based on the daily calorie intake and CPS score, respectively.

Eighteen patients died in the hospital during the study. Therefore, we separately analyzed the data regarding the primary outcome. Table 2 shows outcome-related variables comparing nutritional variables. Malnourished patients were likely to not return home in both overall and survival cases (both $p<0.001)$ and to stay longer $(p=0.001)$ in the survival cases. Only $52.6 \%$ of the malnourished patients could return home, while $78.1 \%$ of surviving nonmalnourished patients returned home. In the analysis of all cases, patients who returned home had a $13 \%$ larger nutritional intake at the time of admission to the post-acute care ward (27.2 vs $24.0 \mathrm{kcal} / \mathrm{kg} / \mathrm{d}, p=0.022$ ). ADL assessed using BI were lower in malnourished patients than in patients with nutritionally intact status ( $p=0.003$ ). The reasons for admission to the acute care ward did not differ between patients returning home and the others in both the overall and survival cases $(p=0.665$ and $p=0.592$, respectively). Therefore, for the multivariate analyses, we did not adjust for the reasons for admission which were categorized into 9 groups, to avoid an overfit or a poor fit of the model due to increasing parameters. ${ }^{20}$

Table 3 shows the results of the Cox proportional regression analyses of patients returning home. Malnutrition was independently associated with not returning home and accounted for approximately $48 \%$ lesser chance of returning home (hazard ratio: $0.517,95 \%$ confidence interval: $0351-0.761, p=0.001)$. Other nutritional variables such as the amount of nutritional intake, OHAT, BI, and CPS no longer had a significant association with returning home. Similar results were observed using survival cases.

Table 4 shows the results of a multivariable linear regression analysis of $\mathrm{BI}$ at discharge in the survival cases. Increased nutritional intake was an independent contributor to $\mathrm{BI}$ at discharge after adjusting for variables in the acute care ward (standardized coefficient: 0.099, $p=0.021$ ). BI and CPS at the time of admission were also associated with BI at discharge $(p<0.001$ and $p=0.015$, respectively). However, malnutrition was not an independent factor for BI at discharge $(p=0.424)$.

\section{Discussion}

This prospective observational study evaluated 207 elderly adults who had lived in their homes before the onset of a disease for which they were admitted to the post-acute ward. The study aimed to determine whether nutritional variables had any influence on their returning home after post-acute care.

Table 3 Cox proportional regression analyses for return home

\begin{tabular}{llll}
\hline & $\begin{array}{l}\text { Hazard } \\
\text { ratio }\end{array}$ & $95 \% \mathbf{C l}$ & p-value \\
\hline Malnutrition & 0.517 & $0.35 \mathrm{I}-0.76 \mathrm{I}$ & $0.00 \mathrm{I}$ \\
Nutritional intake, $\mathrm{kcal} / \mathrm{kg} / \mathrm{d}$ & $\mathrm{I} .00 \mathrm{I}$ & $0.989-\mathrm{I} .023$ & 0.489 \\
OHAT & $\mathrm{I} .04 \mathrm{I}$ & $0.940-\mathrm{I} .15 \mathrm{I}$ & $0.44 \mathrm{I}$ \\
$\mathrm{BI}$ at admission to post-acute ward & $\mathrm{I} .006$ & $0.996-\mathrm{I} .015$ & $0.24 \mathrm{I}$ \\
CPS & $\mathrm{I} .013$ & $0.874-\mathrm{I} .173$ & 0.868 \\
Rehabilitation by PT & 0.566 & $0.386-0.829$ & 0.003 \\
\hline
\end{tabular}

Notes: Each variable was adjusted for age, sex, the length of stay in the acute ward, $\mathrm{CCl}$, and premorbid $\mathrm{Bl}$ as well as the length of stay in the post-acute care ward.

Abbreviations: $\mathrm{Bl}$, Barthel Index; $\mathrm{CCl}$, Charlson comorbidity index; $\mathrm{Cl}$, confidence interval; CPS, Cognitive Performance Scale; OHAT, Oral Health Assessment Tool; PT, physical therapist. 
Table 4 Multivariable linear regression analyses for ADL at discharge

\begin{tabular}{llll}
\hline & Coefficient \pm SE & $\begin{array}{l}\text { Standardized } \\
\text { coefficient }\end{array}$ & $p$-value \\
\hline $\begin{array}{l}\text { Malnutrition } \\
\text { Nutritional intake, }\end{array}$ & $2.35 \pm 2.93$ & 0.035 & 0.424 \\
$\mathrm{kcal} / \mathrm{kg} / \mathrm{d}$ & $0.34 \pm 0.15$ & 0.099 & 0.021 \\
OHAT & $1.04 \pm 0.75$ & 0.058 & 0.165 \\
$\mathrm{Bl}$ at admission to & $0.32 \pm 0.07$ & 0.307 & $<0.001$ \\
$\begin{array}{l}\text { post-acute ward } \\
\text { Cognitive }\end{array}$ & $-2.45 \pm 1.00$ & -0.130 & 0.015 \\
$\begin{array}{l}\text { performance scale } \\
\text { Rehabilitation by PT }\end{array}$ & $-1.74 \pm 2.96$ & -0.026 & 0.558 \\
\hline
\end{tabular}

Notes: Each variable was adjusted for age, sex, the length of stay in the acute ward, $\mathrm{CCl}$, and premorbid $\mathrm{BI}$ as well as the length of stay in the post-acute care ward.

Abbreviations: ADL, activities of daily living; $\mathrm{BI}$, Barthel Index; $\mathrm{CCl}$, Charlson comorbidity index; OHAT, Oral Health Assessment Tool; PT, physical therapist.

The study revealed that 1) ESPEN-defined malnutrition predicts a poor possibility of returning home and 2) high nutritional intake at admission may lead to a higher ADL at discharge.

Both univariate and multivariable analyses showed that ESPEN-defined malnutrition was negatively associated with returning home in post-acute care patients. The nutritional status is defined by not just body weight but also physical functioning, muscle and fat mass, and nutritional intake. ${ }^{21}$ Patients with cognitive impairment are frequently malnourished. ${ }^{22,23}$ Several studies have reported that limited mobility, inactivity, swallowing disorder, and cognitive impairment are risk factors for not returning home from post-acute settings. ${ }^{3,8,24}$ These findings possibly indicate that malnutrition is an independent risk factor for not returning home and, therefore, support our results. However, Thomas et $\mathrm{a}^{6}$ have reported no significant differences in the destinations after discharge among 3 groups categorized on the basis of BMI ( $<22 \mathrm{~kg} / \mathrm{m}^{2}, 22-27 \mathrm{~kg} / \mathrm{m}^{2}$, and $\left.>27 \mathrm{~kg} / \mathrm{m}^{2}\right)$ or between 2 groups categorized on the basis of MNA $(<17$ points and 17-23.5 points), though these analyses were performed without adjusting for confounding factors. As described in the report, there was no standard method to diagnose malnutrition. We implemented a validated ESPENdefined process to diagnose malnutrition, which comprised of risk screening using a validated screening tool and 3 options to determine the nutritional status. ${ }^{15,25}$ Conclusions were made based on the results of multivariate analyses.

ADL at discharge from post-acute ward was influenced by nutritional intake at admission. Although ADL is well known as a factor influencing discharge to home, ${ }^{8,24,26,27}$ little is known about factors influencing ADL at discharge. We found that the amount of nutritional intake during the first 3 days after admission was higher in patients who ended up returning home $(27.2 \pm 8.6 \mathrm{kcal} / \mathrm{kg} / \mathrm{d})$ than in those who did not return home $(24.0 \pm 10.8 \mathrm{kcal} / \mathrm{kg} / \mathrm{d}, p=0.022)$. Therefore, it might be possible to improve the chances of returning home through ADL improvement by providing nutritional support in post-acute settings. While this study was an observational study, an interventional study would be ideal to determine causality between nutritional intake and outcomes. The interventional methods that can enable older adult patients to be successfully discharged should be determined by a multidisciplinary approach. ${ }^{28}$ The results of this study point to the importance of nutritional assessment and care in a geriatric multidisciplinary center.

Based on our results, we suggest that nutritional status should be assessed immediately upon admission to screen for patients who are likely not to return home. We also suggest that the nutritional intake should be increased if patients are found to be malnourished. These procedures cannot always be performed by dietitians, and multidisciplinary collaboration will be expected. The multidisciplinary approach focused on nutrition and functional status to improve the physical functioning and not develop disability is known as "rehabilitation nutrition" and is performed by a combination of nutritional and functional management experts. ${ }^{29}$ The rehabilitation nutrition especially pays attention to nutritional status, nutritional intake, and muscle mass and function (sarcopenia). ${ }^{29}$ Screening of patients to determine their nutritional status is important for the development of targeted nutritional care within the rehabilitation settings ${ }^{30}$ in order to help them return home and avoid ADL decline.

There are several limitations in the study. First, reasons for admission to acute care hospital were not considered in the multivariable analyses. The influence of diseases was not eliminated in the study. Second, this is an observational study. An interventional study, especially a randomized controlled one, can clarify the causality between factors and outcomes. Third, an accurate measurement of the nutritional intake might be biased, since the malnourished patients had a higher nutritional intake. When divided by actual body weight, the underweight patients had a higher nutritional intake than normal or overweight patients.

\section{Conclusion}

Malnutrition and poor nutritional intake at admission to post-acute setting are determinants of returning home and ADL level at discharge, respectively. Screening nutritional risk, assessing nutritional status, monitoring the amount of dietary intake, and following nutritional care may contribute to favorable outcomes for patients in post-acute settings. 
A future interventional study focusing on nutritional management in a post-acute setting should be conducted.

\section{Acknowledgment}

This research was supported by a grant-in-aid (28-01-003)

from the Japan Primary Care Association (http://www. primary-care.or.jp/jpca eng/index.html).

\section{Disclosure}

The authors report no conflicts of interest in this work.

\section{References}

1. Marshall S, Bauer J, Isenring E. The consequences of malnutrition following discharge from rehabilitation to the community: a systematic review of current evidence in older adults. J Hum Nutr Diet. 2014;27: 133-141.

2. Gozalo P, Leland NE, Christian TJ, Mor V, Teno JM. Volume matters: returning home after hip fracture. J Am Geriatr Soc. 2015;63: 2043-2051.

3. Hakkarainen TW, Arbabi S, Willis MM, Davidson GH, Flum DR. Outcomes of patients discharged to skilled nursing facilities after acute care hospitalizations. Ann Surg. 2016;263:280-285.

4. Kushner DS, Peters KM, Johnson-Greene D. Evaluating Siebens Domain Management Model for inpatient rehabilitation to increase functional independence and discharge rate to home in geriatric patients Arch Phys Med Rehabil. 2015;96:1310-1318.

5. Visvanathan R, Penhall R, Chapman I. Nutritional screening of older people in a sub-acute care facility in Australia and its relation to discharge outcomes. Age Ageing. 2004;33:260-265.

6. Thomas DR, Zdrowski CD, Wilson MM, et al. Malnutrition in subacute care. Am J Clin Nutr. 2002;75:308-313.

7. Massucci M, Perdon L, Agosti M, et al. Prognostic factors of activity limitation and discharge destination after stroke rehabilitation. Am J Phys Med Rehabil. 2006;85:963-970.

8. Chang FH, Ni P, Jette AM. Does activity limitation predict discharge destination for post-acute care patients? Am J Phys Med Rehabil. 2014;93:782-790.

9. Guigoz Y. The Mini Nutritional Assessment (MNA) review of the literature - What does it tell us? J Nutr Health Aging. 2006;10 466-485.

10. Kaiser MJ, Bauer JM, Ramsch C, et al. Frequency of malnutrition in older adults: a multinational perspective using the mini nutritional assessment. J Am Geriatr Soc. 2010;58:1734-1738.

11. Cederholm T, Bosaeus I, Barazzoni R, et al. Diagnostic criteria for malnutrition - An ESPEN Consensus Statement. Clin Nutr. 2015;34: 335-340.

12. Kaiser MJ, Bauer JM, Ramsch C, et al. Validation of the Mini Nutritional Assessment short-form (MNA-SF): a practical tool for identification of nutritional status. $J$ Nutr Health Aging. 2009;13:782-788.

13. Toniazzo MP, Amorim PS, Muniz FW, Weidlich P. Relationship of nutritional status and oral health in elderly: systematic review with meta-analysis. Clin Nutr. In press 2017.
14. Maeda K, Shamoto H, Wakabayashi H, Enomoto J, Takeichi M, Koyama T. Reliability and validity of a simplified comprehensive assessment tool for feeding support: Kuchi-Kara Taberu index. $J$ Am Geriatr Soc. 2016;64:e248-e252.

15. Maeda K, Koga T, Nasu T, Takaki M, Akagi J. Predictive accuracy of Calf circumference measurements to detect decreased skeletal muscle mass and european society for clinical nutrition and metabolism-defined malnutrition in hospitalized older patients. Ann Nutr Metab. 2017; 71:10-15.

16. Chalmers JM, King PL, Spencer AJ, Wright FA, Carter KD. The oral health assessment tool - validity and reliability. Aust Dent J. 2005;50: 191-199.

17. Mahoney FI, Barthel DW. Functional evaluation: the Barthel index. Md State Med J. 1965;14:61-65.

18. Charlson ME, Pompei P, Ales KL, MacKenzie CR. A new method of classifying prognostic comorbidity in longitudinal studies: development and validation. J Chronic Dis. 1987;40:373-383.

19. Morris JN, Fries BE, Mehr DR, et al. MDS cognitive performance scale. J Gerontol. 1994;49:M174-M182.

20. Harrell FE Jr, Lee KL, Mark DB. Multivariable prognostic models: issues in developing models, evaluating assumptions and adequacy, and measuring and reducing errors. Stat Med. 1996;15:361-387.

21. White JV, Guenter P, Jensen G, et al. Consensus statement: Academy of Nutrition and Dietetics and American Society for Parenteral and Enteral Nutrition: characteristics recommended for the identification and documentation of adult malnutrition (undernutrition). J Parenter Enteral Nutr. 2012;36:275-283.

22. Maeda K, Akagi J. Cognitive impairment is independently associated with definitive and possible sarcopenia in hospitalized older adults: the prevalence and impact of comorbidities. Geriatr Gerontol Int. Epub 2016 June 7.

23. Favaro-Moreira NC, Krausch-Hofmann S, Matthys C, et al. Risk factors for malnutrition in older adults: a systematic review of the literature based on longitudinal data. Adv Nutr. 2016;7:507-522.

24. Everink IH, van Haastregt JC, van Hoof SJ, Schols JM, Kempen GI Factors influencing home discharge after inpatient rehabilitation of older patients: a systematic review. BMC Geriatr. 2016;16:5.

25. Guerra RS, Fonseca I, Sousa AS, Jesus A, Pichel F, Amaral TF. ESPEN diagnostic criteria for malnutrition - a validation study in hospitalized patients. Clin Nutr. Epub 2016 Sep 8.

26. Ishizaki T, Kai I, Hisata M, Kobayashi Y, Wakatsuki K, Ohi G. Factors influencing users' return home on discharge from a geriatric intermediate care facility in Japan. J Am Geriatr Soc. 1995;43:623-626.

27. Nguyen VQ, PrvuBettger J, Guerrier T, et al. Factors associated with discharge to home versus discharge to institutional care after inpatient stroke rehabilitation. Arch Phys Med Rehabil. 2015;96: 1297-1303.

28. Ellis G, Whitehead MA, O’Neill D, Langhorne P, Robinson D. Comprehensive geriatric assessment for older adults admitted to hospital Cochrane Database Syst Rev. 2011:CD006211.

29. Wakabayashi H, Sakuma K. Rehabilitation nutrition for sarcopenia with disability: a combination of both rehabilitation and nutrition care management. J Cachexia Sarcopenia Muscle. 2014;5:269-277.

30. Maeda K, Shamoto H, Wakabayashi H, Akagi J. Sarcopenia is highly prevalent in older medical patients with mobility limitation. Nutr Clin Pract. 2017;32:110-115.
Clinical Interventions in Aging

\section{Publish your work in this journal}

Clinical Interventions in Aging is an international, peer-reviewed journal focusing on evidence-based reports on the value or lack thereof of treatments intended to prevent or delay the onset of maladaptive correlates of aging in human beings. This journal is indexed on PubMed Central, MedLine,

\section{Dovepress}

CAS, Scopus and the Elsevier Bibliographic databases. The manuscript management system is completely online and includes a very quick and fair peer-review system, which is all easy to use. Visit http://www.dovepress. com/testimonials.php to read real quotes from published authors. 